tando a arquitetura como superartefato e paisagem, sendo o próprio edifício uma paisagem construída.

A seguir, o capítulo II imerge no locus de pesquisa: o núcleo histórico da Praça Frei Caetano Brandão, hoje conhecido como Feliz Lusitânia, e suas relações com a existência do sofrido Centro Histórico de Belém. O autor trata da sobreposição de paisagens no Centro Histórico, entendidas pela trajetória da longa duração do lugar, descrevendo a ocupação do núcleo e sua ressignificação como cenário de poder no início dos anos 2000. No terceiro capítulo, ele apresenta contribuição específica sobre a configuração do artefato arquitetônico nos relatos dos séculos XVII e XVIII. Por meio dos discursos dos religiosos inacianos sobre a paisagem de Belém e de outros relatos, perfaz a cronologia construtiva do edifício, oscilando entre a representação e a percepção. Rhuan Carlos tece uma dissertação em profundidade, imbricando arquitetura e formulações ideológico-pedagógicas dos jesuítas em sua ocupação do território colonial situado no Norte brasileiro. Desenvolve a cronologia em três momentos: na primeira etapa, em que a sede dos missionários situava-se no bairro da Campina; na segunda fase, com estruturas ainda precárias, quando se evidenciam os descompassos entre mão de obra e arquitetura; e a terceira etapa, na qual igreja e colégio destacam-se no cenário mais importante da sede da Capitania Grão-Pará e Maranhão.

Do silêncio de suas paredes, o antigo colégio e a igreja dos jesuítas clamam para ter sua história revista, como nos demonstra a fala de um morador da Praça Frei Caetano Brandão, que não se sente impressionado pelo espaço musealizado do antigo colégio, tampouco gosta da igreja dotada de ar-condicionado e poltronas estofadas: "mas eu era mais aquela antiga", dos gavetões dos altares banhados a ouro, do sino em carrilhão, da ambiência sagrada. A obra de Rhuan Carlos nos convida para este passeio, sinalizando no presente o lugar do achado, pois só assim o investigador crítico pode contribuir para a compreensão da sociedade contemporânea.

PITARCH, Pedro. 2013. O lado oculto da dobra. Ensaios de antropologia indigena. México, DF: Artes de México y Del Mundo/ Conaculta. 231 pp.

\section{Francisco Pazzarelli}

Instituto de Antropologia de Córdoba - Conicet Universidad Nacional de Córdoba, Argentina

Qual é o lado oculto da dobra? Os maia-tzeltales de Cancúc, nos Altos de Chiapas (México), possuem uma existência solar: um mundo de formas definidas, com corpos que projetam sombras. O "Outro Lado", de vital importância para os tzeltales, é um mundo lunar e corresponde ao território ontológico das almas, dos mortos e dos espíritos: um mundo de indefinição, onde nenhuma forma encontra-se estabilizada. A "dobra" constitui o articulador metafísico entre ambos os lados: um intervalo de intensidade que habilita a existência solar à custa da retenção temporária de uma parte de almas alheias. O lado oculto da dobra, então, não é (apenas) um recurso retórico: aponta para uma filosofia indígena e assinala o caminho do projeto intelectual de Pedro Pitarch que os ensaios deste livro se ocupam em apresentar e resumir.

Os nove textos que conformam esta compilação, baseados numa etnografia realizada entre finais dos anos 80 e início dos anos 90, atualizam uma série de debates já propostos em trabalhos precedentes, oferecendo uma perspectiva 
original sobre o mundo indígena mesoamericano. O argumento central é articulado em torno de três eixos/conceitos que se apresentam como fundamentais: corpo, alma e texto. Deles desdobra-se uma extensa série de problemas que incluem as noções indígenas de doença, a complexa relação de corpo e alma com a alteridade, a escrita e a tradução. Como categoria analítica que percorre todos os capítulos encontra-se a dobra: figura instalada entre os planos do corpo e da alma que permite passar de um "lado" para o "outro". Interessa-me sublinhar aqui três movimentos indispensáveis que o autor realiza com seu argumento: as consequências da dobra do corpo no mundo solar, a dobra de almas alheias e sua relação com o "Outro Lado", e o texto introduzido na dobra.

A respeito do primeiro assunto, talvez seja a descrição da formação do feto, nos capítulos iniciais, que melhor expressa a mediação que encarna a dobra. Durante a gestação, o feto está "pelo avesso" e é durante o nascimento que se dobrará sobre si mesmo, arrastando as almas que estavam soltas, em contato com a placenta. Como consequência desse movimento, elas passarão a morar nesse corpo dobrado que nascerá no mundo solar dos tzeltales. Nesse mesmo momento, um duplo dessas almas irá morar no interior de uma das quatro montanhas (uma para cada patrilinhagem), que concentram conjuntamente a totalidade das almas tzeltales. Esses corpos solares têm em seu início uma existência precária, que pode se desdobrar facilmente se não forem cuidadosamente alimentados e educados. Assim, enquanto a vida se expressa como uma luta para evitar um desdobramento involuntário e para manter o corpo fechado (crianças pequenas e pessoas doentes são especialmente vulneráveis), a morte constitui o momento do desdobramento total, quando aquela "identidade" pessoal solar vai se abrir finalmente para retornar à indefinição característica do "Outro Lado".

Essa relação corpo-alma ressoa em boa parte da etnologia da Amazônia e da Melanésia, onde são reportadas relações similares: uma indistinção compartilhada das "almas" perante uma diferença corporal intensamente fabricada, como suposto pelo "multinaturalismo" conceituado por Eduardo Viveiros de Castro, ou a relação entre o dado e o inventado feita por Roy Wagner. Relações deste tipo são exploradas no livro a partir de diferentes ângulos, incluindo a "conversão (religiosa) dos corpos" mesoamericanos, por exemplo. Esses diálogos etnológicos são mencionados por Pitarch desde o início, mas sua resolução está longe de ser um modelo dual de corpo-alma. O modelo maia-tzeltal é quaternário e supõe diferentes variações e combinações entre "corpos" e "almas" que permitem apreender a diferença (sempre parcial e instável) entre entes classificados como "humanos", "animais" ou "espíritos".

Além do acima descrito, está o segundo aspecto que gostaria de destacar: a existência solar tzeltal possui um componente de alteridade indispensável, já que as almas incorporadas durante o nascimento são sempre "outras": pertencem ao "Outro Lado" e estão capturadas só de maneira temporária na dobra solar. A pessoa, assim, é uma "dobra do lado de fora"; e esse "fora" está conformado, por exemplo, por múltiplos afetos animais, mas especialmente por almas europeias (curas, escrivãs, governantes). Esse lado não humano, povoado por uma comunidade de almas dentro das montanhas, se constitui como uma cidade europeia e branca que desfruta de uma ordem extrema. Porém, tudo isso é assim somente desde a perspectiva (solar) dos tzeltales. Desde a perspectiva própria das almas, a montanha é vista e vivida de forma muito diferente: um local de festa (embora festa 
de tipo citadina), onde a música e o álcool não param nunca de circular e colaboram com a desordem e a indistinção.

Essa diferença permite a Pitarch estabelecer algumas análises comparativas com a noção de "ponto de vista" desenvolvida na etnologia amazônica. O autor expõe que a dupla perspectiva (que poderia ser desdobrada para muitas outras, segundo o número de almas dobradas) é interior para cada um e corresponde aos diferentes "quem de uma pessoa": assim, cada teztal reúne em si mesmo "um ramalhete de perspectivas e, portanto, de sujeitos" (:118). Esses diferentes pontos de vista, além disso, apontam com precisão o componente de alteridade das almas tzeltales, pois ambas as perspectivas sobre a montanha estão vinculadas com experiências "castelhanas": tanto a cidade organizada quanto a festa interminável correspondem a gradações máximas dos estereótipos citadinos que não fazem parte da experiência tzeltal cotidiana. O ponto de vista guardado na dobra é sempre um "outro".

Pitarch aponta que essas almas são mais "acontecimentos" do que "seres": experiências passadas de práticas econômicas ou processos institucionais que estão introjetados nas dobras e que se constituem, por força própria, em memória. Em outras palavras, o corpo carrega no seu interior uma história de longo prazo que pode ser recuperada a partir dos corpos atuais, habilitando conexões parciais entre as experiências solares dos tzeltales e aquelas experiências passadas que, contidas no "Outro Lado", se estabelecem simultaneamente como atemporais e com a capacidade de serem experimentadas de novo. Essas reflexões têm uma especial relevância para pensar sobre os modos em que opera a memória social em grupos indígenas americanos.

Como percebido, a dobra sempre se apresenta como conexão parcial com o
"Outro Lado", permitindo certa comunicação e salvando a diferença ontológica entre ambos os territórios. A análise dos santos das igrejas é esclarecedora a este respeito: os santos têm uma existência precária porque têm dobrado seus corpos somente de maneira parcial para poderem se encontrar com as pessoas no lado solar sem perderem sua conexão com o "Outro Lado". Por isso, os tzeltales devem vesti-los e fabricar-lhes roupas constantemente: é preciso embrulhá-los para que possam continuar existindo no mundo solar. Mas nem sequer o corpo tzetal mais bem fabricado é completamente fechado: as dobras sempre são susceptíveis de serem penetradas por doenças. Este é outro desdobramento que chamou a atenção de Pitarch desde o primeiro momento, pois a relação ontológica que a dobra habilita é desenvolvida, na maioria das vezes, na forma de doença: o mal do texto, entre outras.

O fascínio dos maias-tzeltales com a linguagem e especialmente com a escrita e os textos faz parte de uma lógica à qual o autor se dedica densamente e que compõe o terceiro eixo que gostaria de salientar aqui. A linguagem, como afirmado em várias passagens, é doença para as pessoas e pode entrar nos corpos como um agente patógeno. Os textos se comportam como entes intencionados, que saem da boca de espíritos e almas para atacar as pessoas, instalando-se nos interstícios de suas dobras, aproveitando aqueles espaços de comunicação interespecífica, mais sensíveis àquilo que é estranho. Quando os seres do "Outro Lado" falam ou fazem barulho (nada de estranhar, considerando que moram numa festa contínua), os tzeltales adoecem; pelo contrário, o silêncio deles é saúde. Curar então é silenciar o "Outro Lado": durante o encontro cosmopolítico que supõe cada processo de cura, os xamãs dialogam não para deter um conflito, mas para combater e ver quem vai calar 
primeiro. É por isso que a fabricação do corpo envolve de maneira tão intensa a etiqueta da linguagem; ainda mais quando a palavra é escrita, um traço que define a existência das almas e dos entes perigosos do "Outro Lado".

Poder-se-ia dizer que o livro de Pedro Pitarch se ocupa das variações na relação "corpo" e "alma", óbvio. Mas isto não seria o bastante. Pois corpo, alma, texto, doença, memória, santos, perspectiva, tudo isto se encontra em Cancúc dobrado sobre si mesmo, e simultaneamente desdobrado para o infinito. Pitarch, então, se ocupa disso: da dobra. Pedra-de-toque da diferença ontológica entre o "Outro Lado" e este aqui, a dobra é fundo e figura de uma relação complexa e fractal, projetada para infinitas dimensões. E da mesma forma em que não é possível cortar uma fita de Moëbius para adivinhar qual dos seus lados estava dentro e qual estava fora, a dobra é acompanhada nas suas dobras e torções. Acredito que este é o movimento, aliás muito interessante, que o livro propõe: sem fragmentar as dobras tzeltales, ocupa-se em seguir suas fronteiras e em multiplicar os olhares possíveis sobre elas, revelando aqueles beija-flores, jaguares e escrivãs espanhóis que, diante da mínima dobra, escapam para nos enfrentar e nos lembrar que sempre fomos "outros".

RENOLDI, Brígida. 2013. Carne de Carátula. Experiências etnográficas de pesquisa, julgamento e narcotráfico. La Plata: Edições Al Margen. 327 pp.

\section{Daniel P. Míguez}

Universidad Nacional del Centro de La Provincia de Buenos Aires

No campo dos estudos sobre Estado e crime na Argentina, as agências públicas tinham sido habitualmente retratadas como dispositivos que agiam "sobre" a sociedade civil com um efeito disciplinante. Carne de Carátula intervém nesse campo, integrando um corpo crescente de estudos que propõe uma nova perspectiva: em lugar de ser um agente "externo", o Estado é pensado como um sistema institucional que é configurado na trama de relações sociais que articula agentes públicos com atores da sociedade civil. Em prol desse objetivo, o texto propõe três caminhos inter-relacionados.

Desde suas primeiras páginas sabemos que se trata de uma etnografia que se desenvolve ali, onde se juntam e se separam Brasil, Paraguai e Argentina: suas fronteiras. Nesse espaço, o texto aborda as formas de relação social entre aqueles que transportam e intercambiam substâncias ou objetos que são considerados ilegais (traficantes), aqueles que são encarregados de controlar para que isso não aconteça (guardas) e aqueles que "estabelecem", ex post facto, se isso tem efetivamente acontecido, quem é o responsável e qual punição caberia (juízes e fiscais). Contudo, se um dos percursos nos leva pelo território no qual esses atores intervêm (a floresta, a cidade e as populações rurais), outro leva-nos pelas instituições. E, neste caso, o trânsito não é apenas pela materialidade (escritórios, celas, tribunais), mas pelas práticas que dão lugar a relações sociais que simultaneamente configuram e são configuradas pelas instituições. Nesse trânsito revela-se uma das questões mais significativas.

Se em Carne de Carátula são descritas densamente as interações cotidianas entre os atores, naquelas em que o tráfico e seu pretenso controle e julgamento acontecem, é para mostrar que nessas interações "age-se", e nessas atuações o Estado cobra substância fática. Como declarado pela autora: "no movimento o Estado se faz...". O terceiro percurso 